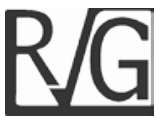

\title{
Economía ética hermenéutico-crítica y su gestión en las organizaciones*
}

\author{
Calvo, Patrici**
}

\section{Resumen}

El actual proceso de globalización económica constituye uno de los grandes retos de nuestro tiempo. Las éticas aplicadas pueden ofrecer pautas y orientaciones para poder afrontarlo correcta y exitosamente. Sin embargo, son muchas las reticencias al abordar la gestión de la ética en el ámbito económico por su supuesta vinculación con la disminución de un máximo beneficio. Siguiendo una metodología propia de la filosofía moral, el de analizar las fuentes bibliográficas para interpretar y reflexionar críticamente sus ideas, conceptos y teorías, los resultados de la investigación han permitido evidenciar que, por un lado, dar la espalda a la ética resulta contraproducente para la práctica económica, y que, por otro lado, es posible su gestión en las organizaciones económicas mediante la aplicación e implementación de un sistema de monitorización y gestión de la ética estructurado alrededor de cinco mecanismos de comunicación. Como conclusión, el estudio sugiere que aplicar e implementar en las organizaciones un enfoque hermenéutico-crítico de economía ética como el desarrollado por Jesús Conill a través de este sistema de gestión, permite afrontar los retos que subyacen al proceso actual de globalización económica.

Palabras clave: ética dialógica; sistema de monitorización y gestión de la ética; racionalidad económica; globalización económica.

Recibido: 29-07-13 Aceptado: 16-04-15

* Este estudio se inserta en el Proyecto de Investigación Científica y Desarrollo Tecnológico FI2013-47136-C2-2-P, financiado por el Ministerio de Economía y Competitividad y con Fondos FEDER de la Unión Europea, y en las actividades del grupo de investigación de excelencia PROMETEO/2009/085 de la Generalitat Valenciana.

** Profesor de ética en el Departamento de Filosofía y Sociología de la Universitat Jaume I de Castellón (España). E-mail: calvop@fis.uji.es 


\title{
Economic Hermeneutic-critical ethics and its management in organizations
}

\begin{abstract}
The current economic globalization process constitutes one of the greatest challenges of our times. The applied ethics may offer guides and orientations for facing it correctly and successfully. Nevertheless, there are many reticences when it comes to approaching the management of the economic ethics due to its alleged association with decreased maximum benefit. Following a methodology proper of moral philosophy, analyzing bibliographic sources to interpret and critically reflect their ideas, concepts and theories, the research results have allowed to demonstrate the fact that on one side, turning the back on ethics results counterproductive for the economic practice, and on the other side its management is possible in the economic organizations through the application and implementation of a monitoring system and ethics management structured around five communication mechanisms. As conclusion, the study suggest that applying and implementing in the organizations an hermeneutic-critical ethic economic approach as the developed by Jesús Conill allows to face the challenges underlying the current economic globalization process.
\end{abstract}

Key words: dialogic ethics; monitoring system and ethics management; economic rationality; economic globalization.

\section{Introducción}

A lo largo de los años setenta del siglo $\mathrm{XX}$ comenzaron a gestarse las éticas aplicadas. En aquellos momentos la fundamentación de lo moral continuaba siendo el principal foco de atención de la reflexión ética, sin embargo, poco a poco se fue generando una cada vez mayor preocupación por cómo aplicar todo ese bagaje adquirido sobre contextos concretos de praxis social. Sobre todo, porque las distintas perspectivas de máximos que comenzaban a caracterizar las diferentes sociedades de un mundo, cada vez más globalizado, se estaban convirtiendo en un problema para el logro de la convivencia pacífica de sus ciudadanos, de su desarrollo y de su subsistencia (Cortina, 2003:13-14).

De esta forma, la aplicación de la ética se fue configurando alrededor de una tarea básica: reflexionar sobre los principios, valores, y procedimientos que deberían ser tenidos en cuenta por los distintos afectados por una actividad social determinada (Cortina y Martínez, 1996:151). Una labor cuya pretensión no era proporcionar soluciones inmediatas a los problemas y conflictos concretos, sino ofrecer un marco de referencia desde el cual prescribir de forma mediata la gestión y toma de decisiones en cada ámbito de actividad (Cortina, 1996:121).

Esta cuestión de fondo permite establecer una doble función para las éticas aplicadas. Por una parte, desde una perspectiva práctica, ayudar en la resolución de aquellos conflictos sociales que reclaman su cooperación. $\mathrm{Y}$ por la otra , en el ámbito teórico, "cooperar en la configuración de una autocrítica de la filosofía moral, proporcionando técnicas de argumentación y análisis que pueden ayudar a la gente a responder frente a los juicios de valores", así como proporcionar argumentos válidos que justifiquen las prescripciones morales 
y prueben la validez de los principios aplicados (González, 2001:89). Es, por consiguiente, un giro que surge "más que por 'imperativo filosófico', por imperativo de una realidad social que las necesitaba en sociedades moralmente pluralistas" (Cortina, 2003:13-14). Es decir, como una respuesta a las exigencias de la sociedad, de los Estados, de los ciudadanos, de los profesionales, de los académicos y de la red de organizaciones y asociaciones de la sociedad civil (Camps y Cortina, 2007:445-446).

En el caso concreto de la praxis económica, como sugiere el premio nobel de economía Sen (2003), la búsqueda de modelos orientativos que permitan reflexionar sobre cómo dirigirla hacia ese nuevo horizonte de sentido que subyace tras el nuevo orden mundial global, puede encontrar en la ética económica una fuente importante de inspiración. Sobre todo porque su principal labor es, precisamente, buscar el modo de configurar desde la propia praxis un marco reflexivo a través del cual poder prescribir de forma mediata tanto la actividad economía como el diseño de las instituciones, organizaciones y empresa que la desarrollan.

Por todo ello, el objetivo de este estudio será mostrar que la ética es un activo para la economía, así como ofrecer orientaciones para abordar su aplicación e implementación práctica en las organizaciones a través de un sistema de monitorización y gestión. Para ello, en primer lugar se considerará el modelo de ética económica integrativa desarrollado por Peter Ulrich (1993, 2008) como fundamentación discursiva de la actividad económica, un enfoque que se presenta como alternativa plausible a las propuestas concretas de éticas aplicadas.

En segundo lugar se analizarán las potencialidades y características básicas del método hermenéuticocrítico como procedimiento válido para la aplicación de los principios y valores éticos en los distintos contextos de actividad humana.

En tercer lugar, se propondrá el enfoque de economía ética hermenéuticocrítica de Jesús Conill (2000a, 2006b) como justificación dialógica de la práctica económica, el cual muestra la necesidad de interpretar los contextos concretos de actividad humana para conocer qué valores, motivaciones, principios y lógicas propias le subyacen y, de esta forma, aplicar la ética en la praxis económica sin caer en la utopía, el convencionalismo o el exceso de estrategia propio de otras propuestas teóricas ${ }^{1}$.

Finalmente, se propondrá un sistema de monitorización y gestión de la ética que, estructurado alrededor de cinco mecanismos de comunicación complementarios -código de ética y conducta, comité de ética, memoria de ética y responsabilidad corporativa, auditoría ética y línea ética (sistema whistleblowing) - permite gestionar en la práctica organizacional un enfoque de economía ética hermenéutico-crítica como el aquí sugerido.

Para su desempeño, el trabajo se ha desarrollado utilizando un método

Los tres primeros apartados de este artículo están basados en un trabajo previo sobre ética económica y empresarial. Puede consultarse una versión íntegra de esta investigación en la tesis doctoral Racionalidad económica: aspectos éticos de la reciprocidad (Calvo, 2012:73-91). 
comparativo e interpretativo. Por un lado, se ha realizado un estudio comparativo y crítico sobre dos propuestas teóricas relacionadas con la aplicación de la ética discursiva en el ámbito económico, $y$, por otro lado, se han recopilado y comparado datos procedentes de normativas, códigos, directrices nacionales e internacionales sobre sistemas whistleblowing y sistemas de gestión de la ética en organizaciones económicas.

\section{2. Ética económica integrativa como alternativa a las éticas aplicadas}

Durante los años setenta y ochenta del siglo pasado, el filósofo Karl Otto Apel $(1985,2003)$ y el sociólogo Jürgen Habermas (1991, 1999, 2000) propusieron un criterio de fundamentación de lo moral desde el cual poder edificar las bases racionales de una ética cívica (Cortina, 1993:208); es decir, mostraron la racionalidad comunicativa que hay detrás de todos aquellos procesos argumentativos tendentes al entendimiento entre personas que buscan ponerse de acuerdo sobre distintas cosas del mundo, como los valores, normas y principios que orientan, regulan y coordinan la interacción interpersonal.

El principal problema de los principios, normas y valores morales es que se dirigen a todos los seres humanos, sin distinción, lo cual obliga a tener que encontrar la justificación que permita tal universalización. Para ello, la ética discursiva propone transformar discursivamente el principio formal kantiano de autonomía de la voluntad, pasando del yo pienso al nosotros argumentamos (Cortina, 1993:170), mediante el establecimiento de un proceso de diálogo edificado sobre un concepto de persona -en tanto que interlocutor válido capacitado de habla y acción - y de igualdad -en tanto que exigencia de incluir en el proceso a todos los afectado por la norma criticada (García-Marzá, 1992:131-140).

De este modo, el principio formal kantiano se constituye como un principio procedimental (D) 一sólo pueden pretender ser validas aquellas normas que dentro de un discurso práctico puedan gozar del acuerdo de todos los afectados (Habermas, 1999:73, 1991:101) - y un principio de universalización $(U)$ que adquiere en el proceso de diálogo el papel de regla argumentativa.

La ética discursiva es, pues, una propuesta pragmático-trascendental que entiende que sólo el consenso racional de todos los afectados dentro de un proceso argumentativo con ciertas reglas lógicas y con un principio moral procedimental (Cortina, 1993:208) permite discernir la universalidad de una norma, su justicia. Es decir, la ética discursiva no se preocupa por dilucidar qué normas deben orientar las distintas actividades humanas, sino concretar el proceso que hace posible definir una norma como justa.

En el plano de la aplicación sobre el nivel sistémico y económico, la fundamentación de lo moral cuenta actualmente con un buen número de interesantes propuestas, entre las que se encuentran algunas directamente relacionadas con este enfoque pragmáticotrascendental. En este sentido, uno de los planteamientos que ofrece mayores posibilidades, es la propuesta de ética económica integrativa diseñada y desarrollada por Ulrich (1993, 2008) durante las tres últimas décadas. 
La ética económica integrativa es un intento por superar la dualidad que subyace de la racionalidad prefecta y completa elucubrada por la economía moderna durante los siglos XVII y XVIII, aquella que percibe la moralidad como algo coercitivo y ajeno al mundo económico cuya influencia limita la satisfacción de un óptimo beneficio. Sobre todo porque, en la misma línea que Sen (1989), para Ulrich (1993:7-8), tal interpretación repercute negativamente en el desarrollo tanto humano y social como económico dada "la creciente problematización de los efectos globales para la praxis vital de la dinámica 'desencadenada' del sistema”.

Por este motivo, la ética económica integrativa propone transformar la racionalidad económica para que ni excluya la reflexión moral ni opere al margen del modelo axiomatizado, completo y supuestamente consistente de la economía preponderante, un enfoque de corte neoclásico que basa su desarrollo en una razón calculadora que margina la reflexión crítica y se constituye sobre la natural tendencia del agente económico al egoísmo (Ulrich, 1993:9-10). Sobre todo porque, como argumenta Ulrich (1993:8), cada vez es más evidente "que aquello que se presenta como económicamente racional en el marco del sistema económico "dado", no tiene que ser por ello, incondicionalmente, también racional para nuestra praxis vital".

Para Ulrich (1993), los esfuerzos por salvar la brecha abierta por la economía preponderante ha generado dos caminos diferentes pero insuficientes: uno correctivo y otro funcional. Por correctivo se entiende aquel conjunto de ideas y opiniones que tienden a comprenden la ética como una herramienta plausible para intervenir en "los fallos funcionales del sistema económico"; es decir, como un instrumento "correctivo de la racionalidad económica" (Ulrich, 1993:10). Se trataría, pues, de aplicar sobre un contexto económico concreto ciertos criterios universales que permiten reorientar aquellas cuestiones que escapan a la legislación vigente (Ulrich, 1993:11-12). De esta forma la ética se convierte en "guardián externo de la economía” (Casares, 2011:73).

Por funcional se entiende el uso de la ética como herramienta de mejora del funcionamiento de los sistemas económicos (Casares, 2011:73). De esta manera la ética se convierte en un "elemento favorecedor de las relaciones comerciales. (...) un componente funcional del sistema de mercado que se apoya en el sentido del deber y la creatividad" (Casares, 2011:73). Sin embargo, aunque reconoce su enorme potencial, Ulrich entiende que la propuesta no puede explicar ni justificar desde un punto de vista puramente económico "todas las presuposiciones normativas de un sistema económico apto para funcionar" (Ulrich, 1993:2829).

Para salvar las limitaciones que subyacen tanto de la aplicación de una ética económica correctiva —que parece mostrarse como un limitador del beneficio económico-como de una ética económica funcional —que se muestra meramente preocupada por legitimar aquellos mecanismos que funcionan bien cuando se trata de satisfacer objetivos económicos-, Ulrich (1993) propone un enfoque integrativo de ética económica donde la mediación entre racionalidad económica y racionalidad práctica logre revelar "los presupuestos normativos y axiológicos de la racionalidad económica 
misma" para, desde allí, orientar y coordinar aquellas acciones que permite un máximo beneficio para todos los implicados (Conill, 2006b:70).

La propuesta plantea la necesidad de a) reconstruir aquellos mínimos éticos que permiten aquellos procesos de interacción interpersonal implicados en el correcto desarrollo de la actividad profesional; b) trabajar en la interiorización de carácter mínimo deontológico implícito —el del reconocimiento recíproco de las capacidades comunicativas y participativas de todos los implicados y/o afectados por la praxis económica para coordinar la acción y resolver la conflictividad subyacente a través del diálogo y el consenso-; c) acometer un reflexión crítica sobre las preferencias de los agentes que permita clarificarlas y ordenarlas racionalmente de manera que la racionalidad económica pueda reflexionar críticamente sobre sus propios presupuestos normativos y tomar conciencia de la ética que le subyace-, y d) devolver el sistema económico al orden político, institucional y del mundo de la vida de las sociedades moralmente plurales (Caseres, 2011:74; Panchi, 2004:315-319; Ulrich, 1993:40-48).

Se trata, pues, de una ética económica que no viene impuesta ni interna ni externamente, sino que emerge, alimenta y redefine de la relación y el equilibrio entre ambas partes, sometiendo a la razón económica a un proceso continuado de autocrítica sobre su propia identidad, sobre aquellos presupuestos que la conforman y le dan sentido, a través del cual es posible redescubrir la existencia de una ética mínima que es parte constitutiva de sí misma. Un proceso de integración ético-económico que para Ulrich puede ser acometido mediante la propuesta discursiva de Apel (1985) y Habermas (2000), a través de la reconstrucción de las condiciones de posibilidad de la actividad económica; es decir, reflexionando sobre las condiciones pragmáticas del lenguaje que hacen posible "el acuerdo argumentativo sobre las aspiraciones legítimas de todos los implicados en el proceso de creación de valor o de afectados por el mismo" (Ulrich, 2008:112).

Introducirse en esta perspectiva integrativa de economía y ética implica aceptar que la gestión eficiente de los recursos escasos se halla ligada a aquellas cuestiones "sobre el trato ético racional de los conflictos sociales entre todos los involucrados -legitimidad-" (Ulrich, 2008:112). Esto significa que pretender orientar la eficiencia desde una racionalidad carente de reflexión ético-crítica, como es el caso de la economía preponderante, no es posible ni deseable. Entre otras cosas, porque "la solución racional de los conflictos sobre la distribución de los costos y beneficios (internos y externos) del quehacer económico es un problema normativo, que no se puede resolver en categorías de pura racionalidad económica" (Ulrich, 2008:112-113). Por tanto, toda búsqueda de legitimidad racional, que es condición de posibilidad del correcto desarrollo de toda actividad económica, requiere de una transformación de la racionalidad económica en sentido ético, reflexivo y autocrítico que le dé sentido y legitimidad social y moral (Ulrich, 2008:112):

"La exigencia moral incondicional que busca ser reconocida como condición normativa de todo actuar racional, es la de la legitimidad (...). Se trata entonces de extender la idea de racionalidad económica de modo que incluya la legitimidad 'racional' como condición éticoracional constitutiva. Con ello se alcanza la idea de orientación básica para la integración ética de la racionalidad económica". 
Ahora bien, aunque el enfoque integrativo parece adecuado como horizonte de sentido económico, puesto que se introduce en los contextos concretos de actividad humana sin dejarse llevar unilateralmente por el economicismo (Conill, 2006b:71), de la propuesta teórica desarrollada por Ulrich (2008) subyacen ciertas cuestiones que es necesario tener en cuenta para lograr tanto una adecuada integración entre la economía y la ética como su correcta aplicación e implementación en el nivel práctico (Panchi, 2004:324-328).

En primer lugar, porque la única posibilidad que deja abierta Ulrich (2008) para llegar a la objetividad en el ámbito económico - la posición más formal y normativa kantiana - genera que dé la espalda $-\mathrm{y}$ por tanto desaprovecheotras importantes aportaciones del propio enfoque kantiano (Conill, 2006b:71). Entre ellos, su idea de una 'insociable sociabilidad' del ser humano, un concepto que "expresa un dinamismo histórico a través de las tendencias e impulsos naturales del hombre" que puede aplicarse también al mundo económico (Conill, 2006b:206-210). También los sentimientos y las emociones que subyacen tras el compromiso kantiano de respeto mutuo a la dignidad del otro, una competencia que es condición de posibilidad del establecimiento $y$ desarrollo de todo proceso tendente el entendimiento intersubjetivo entre seres dotados de habla y acción (Cortina, 2010).

En segundo lugar, porque el enfoque da excesiva importancia a lo normativo y formal y se olvida del momento hermenéutico que permite "entender más adecuadamente la actividad económica, su racionalidad y algunas nociones a las que el propio Ulrich recurre para interpretarla en el mundo moderno (como, por ejemplo, las de libertad, persona y ciudadanía)" (Conill, 2006b:72).

En tercer lugar, porque la noción de ética aplicada de la que parte Ulrich para criticarla y rechazarla es falaz (por inducción precipitada, entre otras cosas) por varias razones: a) porque que no es verdad que toda propuesta de aplicación de la ética se estructure en base a dos mundos; b) porque su propuesta de ética económica integrativa también es un tipo concreto de ética aplicada; y c) porque no toda ética aplicada está relacionado con un enfoque correctivo o funcional de ética (Conill, 2003a:122-123).

En cuarto lugar, porque los argumentos que esgrime la propuesta se ajustan al conflicto normativo que subyace tras la concepción económica moderna, el de la dualidad de dos lógicas normativas. Este hecho hace que Ulrich acabe discriminando aspectos relevantes como la razón experiencial frente a lo normativo y formal, una argumentación que, como afirma Conill (2006b:75), podría incurrir en falacia abstractiva.

En quinto lugar, porque se preocupa por acometer una trasformación de la racionalidad perfecta y completa del homo oeconomicus mediante un proceso continuado de autocrítica sobre los presupuestos y conceptos fundamentales que la configuran, pero se olvida tanto de incidir en el desarrollo teórico de la economía (Panchi, 2004:324) como de escrutar el papel que juegan los sentimientos y las emociones en los procesos racionales de toma de decisiones económicas (Calvo, 2012, 2013).

$Y$ en sexto lugar, porque la propuesta se centra en la integración del nivel de la fundamentación y del nivel de la aplicación, pero se olvida 
de otro importe y necesario nivel, el de la adecuación de los principios y normas universales; un nivel cuya labor es velar por su correcta aplicación e implementación sobre los contextos de interacción humana (García-Marzá, 2004:124-128).

Por estos motivos, para Conill (2003b, 2006b), García-Marzá (2004) y Panchi (2004) entre otros, el enfoque integrativo de ética económica resulta enriquecedor pero insuficiente, de ahí que todos ellos propongan la necesidad de concretar una propuesta de ética económica que corrija los problemas y subsane las carencias señaladas. Por ejemplo Conill (2003a:124), que presenta una propuesta hermenéuticocrítica que resuelve los déficits del enfoque integrativo mediante el uso de la razón experiencial; es decir, ampliando el concepto de razón comunicativa para evitar el exceso de formalismo y lograr, entre otras cosas, profundizar en los contextos económicos concretos.

De esta forma es posible mostrar desde éstos el sentido ético que subyace de la actividad económica en los procesos reales y en la reflexión teórica tanto económica como ética. Una economía ética como ética aplicada que, de esta forma, "se muestra capaz de captar las peculiaridades de la economía moderna, en particular, de su actual etapa de desarrollo" (Conill, 2003b:9).

\section{Hermenéutica crítica como método de las éticas aplicadas}

Actualmente existen dos líneas preponderantes entre aquellos enfoques de aplicación de la ética que intentan ir más allá de los modelos tradicionales: pragmática y hermenéutica. La mayor virtud de ambos es que consiguen en diferente grado "romper con el modelo tradicional de la teoría ética y acercarse a un enfoque contextualista y situacional" (Conill, 2003a:121), lo cual ha permitido la emergencia y el desarrollo de distintas propuestas que sirven de ayuda para orientar la tarea de las éticas aplicadas .

En este sentido, como muestran diferentes estudios al respecto (Conill, 2000a, 2000b, 2003a, 2003b, 2006a, 2006b y Cortina, 1993, 1996, 2003, 2007), existen al menos tres tipos de discursos sobre la estructura propia de las éticas aplicadas: la casuística tradicional, la nueva casuística, y la doble propuesta de la ética-discursiva presentada por Habermas (2000) por un lado y Apel (1985) por otro. Sin embargo, ninguno de ellos logra satisfacer por entero las expectativas actuales generadas.

Para lograr superar estas tres líneas de aplicación de la ética sobre contextos concretos de actividad humana, Ulrich (1993) propone la ética económica integrativa, que, como se ha criticado en este estudio, no deja de ser una propuesta concreta de ética aplicada que, partiendo de los presupuestos fundamentales de la ética discursiva —el diálogo y el posible entendimiento entre los implicados y/o afectados por la norma-, intenta salvar sin conseguirlo plenamente las deficiencias que subyacen de las propuestas desarrolladas por Apel $(1985,2003)$ y Habermas (1991, 1999, 2000). Especialmente por el déficit hermenéutico que arrastra y que limita su implementación práctica.

Partiendo también de los presupuestos básicos de la ética discursiva, Conill (2006b) y Cortina (2003) defienden como adecuado un modelo hermenéuticocrítico de aplicación de la ética en contextos concretos de actividad humana, el cual se desarrolla alrededor de una idea fundamental: sólo mediante la adecuación 
de lo universal, a través de un proceso circular de interpretación crítica, puede la praxis llegar a convertirse en un momento aplicado capaz de implementarse. Dicho de otro modo, no es posible descontextualizar la norma, desligarla del propio contexto de actividad que le da sentido y credibilidad, como tampoco reducirla a un mero convencionalismo carente del carácter ético-crítico exigido por la realidad global sobre la que se quiere insertar. Por consiguiente, es necesario y también posible encontrar e interpretar hermenéutica y críticamente aquellos principios y valores propios de cada ámbito de la vida social que los modula y regula de por forma diferente (Conill, 2006b:72):

"Esta profundización hermenéutica de la racionalidad discursiva (o comunicativa) puede contribuir de modo esencial a proyectar un pensamiento auténticamente universalista, porque introduce un universalismo más adensado (y capaz de irse espesando), al estar hermenéuticamente orientado. Pues la hermenéutica no sólo incita a ir creando las condiciones de aplicación de la 'ética discursiva' (por ejemplo, en la situación de los que carecen de poder en la actual jungla global), sino también a abrirse a los otros, a las diversas culturas, a lo extraño. No hay que olvidar que la economía, para los clásicos como W. Sombart, era 'economía comprehensiva' (verstehende Nationalökonomie) y que 'compren-der' (verstehen) significa captar el sentido y el espíritu que anima los fenómenos de la vida económica".

Partiendo desde este punto de vista, Conill (2006b) sugiere que el método de las éticas aplicadas no responde a un proceso meramente deductivo, aquel que extrae los principios morales que posteriormente servirán como orientación de la acción de los contextos concretos de actividad económica, o simplemente inductivo, aquel que se reduce a una mera afinidad de pautas máximas de actuación extraídas y fundamentadas a través de la observación empírica, sino circular. Es decir, aquel que aúna el sentido de ambas vías - deductiva e inductivamediante un doble movimiento:

i) Por una lado, penetrando hermenéuticamente en la propia praxis profesional para: a) comprender plenamente los contextos concreto de actividad $y, b)$ aprehender de cada uno de ellos los principios y valores que constituyen la ética cívica pública común a todos los ámbitos de actividad humana; aquellos mínimos de justicia constituidos sobre un doble principio moral: la dignidad humana y el reconocimiento recíproco de las capacidades comunicativas $y$ las competencias emotivas de aquellas personas que se identifican mutuamente como interlocutores cordiales capacitados para entenderse sobre cosas del mundo y para emo-cionarse por uno mismo y por los demás (Cortina, 2003:31, 2010, 2011, 2013, 2014).

ii) Por otro lado, introduciéndose en un proceso de argumentación crítica donde queden incluidos todos los afectados por la norma a aplicar para: a) lograr la legitimidad moral necesaria; b) ahondar en su adecuación para evitar que emerjan contradicciones, ruidos y paradojas que limiten su implementación y desarrollo; y c) profundizar en las posibilidades de concreción existentes sobre cada contexto concreto de actividad humana.

Desde esta perspectiva, la reflexión se introduce en un proceso discursivo que, mediante el análisis interpretativo de las circunstancias, las lógicas, los procesos y las consecuencias de la actividad concreta, intenta discernir 
la validez moral de la norma, sus posibilidades de aplicación y las mejores formas de implementarla. Se trataría, pues, de una propuesta metodológica en sentido hermenéutico-crítico que permite abordar la reconstrucción de dos niveles: el normativo y el fáctico.

En cuanto al nivel normativo, se trata de aclarar y justificar el marco que permite la armonía y perdurabilidad de las sociedades plurales, los derechos fundamentales que garantizan la convivencia pacífica de todos los implicados (Cortina, 1990:239-253). En el nivel fáctico, se trata de introducirse en los diferentes contextos concretos de acción para, desde ahí, generar el marco de actuación que articule y armonice su actividad (Cortina y Martínez, 1996:160164).

De este modo, el quehacer de la racionalidad económica se dirige hacia la identificación del marco normativo que posibilita la coordinación de la acción y permite una interacción pacífica y beneficiosa para los implicados $y / o$ afectados, así como en los principios, valores, virtudes y estrategias sobre los cuales se desarrollan los contextos concretos de cada praxis profesional (Cortina, 2003:21).

\section{Economía ética hermenéutico-crítica como ética aplicada}

Partiendo de este método hermenéutico-crítico de fundamentación, adecuación y aplicación de lo moral, Conill (2000a:2) se introduce en la realidad económica actual para mostrar cómo los procesos de globalización económica —financiera y comercialfacilitados y potenciados por las nuevas tecnologías - de la información y la comunicación- están concretando un nuevo horizonte de sentido para la economía. Por este motivo, entiende que es necesario reflexionar críticamente sobre la globalización ética para no repetir los errores que limitan el desarrollo tanto de la economía como de la sociedad: la aceptación de valores únicamente economicistas.

En este sentido, tras llevar a cabo una revisión de los fundamentos y conceptos básicos de la teoría económica preponderante, Conill (2003b:14-15) siguiere que: a) la ciencia económica es social e histórica, no física $\mathrm{y}$, por tanto, mecanicista como pretende el enfoque económico elucubrado y desarrollado desde la irrupción de la corriente de pensamiento marginalista a finales del siglo XIX; b) la economía se ha empobrecido al dar la espalda a su sentido primario: el de una economía político-ética, lo cual merma sus capacidades para resolver los problemas que subyacen a los nuevos procesos de globalización y, c) la base de la información del hecho económico es insuficiente para hacer mella en el desafío que representa actualmente el desarrollo social y humano (Conill, 2003b:14-15; Sen, 2000, 2003).

La superación de tales cuestiones puede acontecer, según Conill, tras la toma en consideración de dos importantes aportaciones provenientes del enfoque de las capacidades de Sen (2000) y de la ética pública cívica de Cortina (2000, 2010).

En primer lugar, se trataría de incluir la perspectiva seniana de libertad y justicia, ya que a través de ésta es posible "reintroducir en la teoría económica un ineludible trasfondo ético" (Conill, 2003b:15). Se trata de una posición que sintoniza perfectamente "con la transformación discursiva y hermenéutica 
de la concepción kantiana, especialmente en lo que se refiere a la atención de los afectados, a la vida real y a las bases de la información", lo cual permite entender mejor "las situaciones históricas y culturales de la vida humana, en que viven las personas concretas" (Conill, 2006b:197). Por consiguiente, es "a partir de la vida real histórica" desde donde es posible discernir el "valor intrínseco y normativo de la libertad en las mediaciones de la vida económica y en las más diversas culturas" (Conill, 2006b:197).

En segundo lugar, se trataría de reconocer que los valores, principios y normas éticas emergen, enriquecen $y$ purifican en el seno de las sociedades maduras a través del diálogo y el acuerdo intersubjetivo. Se trata de incluir en la propuesta económica hermenéuticocrítica la atención y el respeto que merecen esos "mínimos compartidos entre los ciudadanos que tiene distintas concepciones de hombre, distintas ideas de 'vida buena'; mínimos que les llevan a considerar como fecunda su convivencia" (Cortina, 1993:196). Como aclara la propia Cortina, se trata de los "valores de libertad, igualdad y solidaridad, concretados en los derechos humanos, el valor de la tolerancia activa, así como la imposibilidad de proponer a otros el propio ideal de vida si no es a través del diálogo y el testimonio, componen por el momento el caudal de la ética cívica en las sociedades con democracia liberal" (Cortina, 2000:42).
De este modo, apoyándose en la hermenéutica crítica, el enfoque de las capacidades y la ética pública cívica, Conill (2006b) construye una propuesta de economía ética ${ }^{2}$ que, estructurada alrededor de cuatro categorías fundamentales, es capaz de afrontar los retos actuales derivados de una situación mundial "caracterizada por los procesos de globalización y sus consecuencias" (Conill, 2000a:6-7); un nuevo horizonte que las sociedades plurales con un nivel postconvencional de desarrollo moral exigen atender adecuadamente. A saber (Conill, 2000a):

- Ética de la responsabilidad solidaria: Tanto el utilitarismo como el deontologismo kantiano, el comunitarismo neoaristotélico o hegeliano y el pragmatismo contextualista se han mostrado incapaces de "fundamentar un principio de universalización, mediándolo adecuadamente con las exigencias de las organizaciones e instituciones modernas, de tal manera que puedan superarse las marginaciones y discriminaciones injustas". Por ello, una economía ética a la altura de las expectativas en juego necesita edificarse sobre los cimientos de una ética de la responsabilidad solidaria que lo posibilite.

- Ética universalista: Además de una ética de la responsabilidad solidaria que sea capaz de fundamentar un principio de universalización que no dé la espalda a las lógicas y estrategias de cada práctica concreta,

2 Conill (2006b) prefiere hablar de economía ética y no de ética económica. Al respecto aclara que este cambio del orden de las palabras busca explicitar una idea fundamental de su propuesta: los valores, principios y normas morales no son externos a la propia práctica económica . 
una economía ética a la altura de los actuales procesos de globalización requiere de una ética universalista desde la que sea posible satisfacer aquellas expectativas de solidaridad y justicia propias de "un nivel postconvencional en el desarrollo de la conciencia moral, en el orden económico, político y cultural".

- Ética de las instituciones: Aunque la globalización puede aportar grandes beneficios para la sociedad, la realidad es que actualmente continúan existiendo grandes grupos de excluidos de tales logros. Este hecho hace necesario atender el rediseño de instituciones como el Estado, el mercado y los organismos internacionales desde una perspectiva post-convencional de desarrollo moral; es decir, que el proceso tenga en cuenta a todos los afectados presentes o futuros.

- Ética de la globalización: Los actuales procesos de globalización obligan a instaurar "centros de control de las consecuencias de los dinamismos de la acción colectiva desde un horizonte ético" (Conill, 2000a:7). Este reto exige potenciar una responsabilidad a la altura de los intereses en juego (Govea y Rodríguez, 2009; Zambrano y Marval, 2008); es decir, que se preocupe por las consecuencias globales causadas por acciones colectivas, aquellas "producidas por la aplicación de los conocimientos científicotécnicos y por las decisiones políticoeconómicas" (Conill, 2000a:7).

Ante los procesos de globalización económicos, una economía ética constituida sobre una propuesta de ética universalista, procedimentalista, dialógica, hermenéutica y mínima como la presentada por Conill - a la altura de las expectativas de la sociedad global con un nivel postconcenvional de desarrollo moral- reacciona a los nuevos horizontes económicos tratando de a) hallar su sentido de existir; b) captar las nuevas oportunidades y posibilidades existentes; c) determinar los procesos que posibilitan su cumplimiento; y d) encontrar las mejores formas de orientar tales procesos desde una perspectiva responsable y humanizadora.

De este modo, la propuesta de economía ética hermenéutico-crítica, en tanto que horizonte de sentido económico, trata de hacer posible una globalización ética a través de dotar de sentido la economía mediante la promoción y difusión de los valores básicos implicados: la libertad y la justicia. Este podría ser un camino válido, puesto que, como afirma Conill, evitar ser esclavos de los procesos globalizadores económicos y tecnológicos precisa "cambiar tanto la mente y los hábitos de nuestra vida cotidiana como las estructuras desde un nuevo horizonte de sentido, en el que nos sintamos urgidos por el afán de justicia y nutridos por la solidaridad universal" (Conill, 2000a:7).

Por todo ello, lejos de la homogeneidad motivación y comportamental que configura la racionalidad económica perfecta y completa del homo oeconomicus, parece necesario recopceptualizar el modelo económico preponderante desde ese nuevo horizonte de sentido que, como muestran Ulrich $(1993,2008)$ y Conill (2006b), permite a la economía estar a la altura de lo exigible y deseable por una sociedad plural con un nivel de desarrollo moral postconvencional. $Y$ para ello habría que empezar por revisar, modificar y/o desterrar definitivamente aquellos presupuestos no justificados o anacrónicos que sustentan la teoría 
económica prevalente y que la vuelven más imprecisa y menos enriquecedora. Entre ellos, la errónea concepción de que atender lo moral minimiza las opciones de lograr un óptimo beneficio empresarial; la idea injustificada de que los agentes racionales se comportan siempre de forma autointeresada, o la presuposición de que los valores, sentimientos y principios morales no forman parte del quehacer económico.

Por consiguiente, es cierto que el enfoque técnico ha sido enormemente fructífero para la economía al mejorar su comprensión, especialmente en cuanto a mostrar el sentido de muchas relaciones sociales que son fundamentales para su actividad, pero no es menos cierto que, como señala Sen (1989:27), la economía puede dar mucho más de sí prestando mayor atención a las cuestiones morales que le subyacen, las cuales permiten modular la conducta humana en contextos altamente competitivos como los económicos .

No se trata, pues, de ensalzar una postura para marginar la otra, como así hizo la teoría neoclásica al apostar únicamente por el enfoque técnico en su análisis del hecho económico, sino de complementar el técnico y el moral para generar una económica más rica, fructífera y legítima, proporcionando desarrollo económico al mismo tiempo que social y humano. Una economía que, en definitiva, pueda estar a la altura moral de lo esperado, exigido y deseado por la sociedad global y plural actual.

Sin embargo, tras la crisis global actual emerge la necesidad de encontrar mecanismos adecuados que permitan a las organizaciones económicas gestionar debidamente la dimensión moral que les subyace (Pallares y Eriksson, 2014), propiciando de este modo la satisfacción de un máximo valor tanto estratégico como comunicativo. A ello puede contribuir sustancialmente un sistema de monitorización y gestión de la ética estructurado alrededor de cinco mecanismos de comunicación complementarios: un código de ética y conducta, un comité de ética, una memoria de ética y responsabilidad corporativa, una auditoría ética y una línea ética (basado en un sistema whistleblowing de monitorización del comportamiento ético-legal).

\section{Economía ética hermenéutico-crítica y su gestión en las organizaciones}

Durante la actual crisis económica, el descenso continuado de los niveles de confianza, reputación, reciprocidad y afinidad que los grupos de interés depositan en las organizaciones económicas, bienes comunicativos cuya generación y potenciación son condición de posibilidad de la maximización del beneficio (Calvo, 2014), ha convertido la gestión de la ética en una preocupación para muchas de éstas. Sin embargo, este interés por la legitimidad moral de sus acciones y decisiones se ha topado con la actual desafección participativa de la sociedad civil (Feenstra, 2012), puesto que una participación comprometida de éstos se halla detrás de la posibilidad de poder aplicar e implementar una propuesta como la economía ética hermenéutico-crítica aquí abordada.

Este hecho se debe, principalmente, a los continuos escándalos de malas prácticas por corrupción (Pontevedra y Hermida, 2014 y Comas, 2007), malversación de caudales públicos (Gómez y Méndez, 2014 y Rincón et al, 2014), fraude fiscal (Pozzi, 2006), nepotismo (Fernández, 2010), 
politización de los gobiernos corporativos (Noceda, 2010), constitución de cárteles y lobbies (Faus, 2013 y Traynor, 2014), poca o nula sensibilidad hacia el entorno humano y social (Escario, 2014), entre otros. Por tanto, no sólo se buscan mecanismos de comunicación capaces de abordar la relacionalidad interna y externa de la organización económica, sino competentes para fomentar y motivar la participación de los afectados e interesados en los distintos procesos de toma de decisiones.

En este sentido, Donati (2013), Donati y Calvo (2014); Feenstra (2012), Feenstra y Casero (2014), Calvo y Eriksson (2014) han observado que tal desafección de la sociedad civil sólo se da en aquellos mecanismos y procesos de participación convencionales. Prueba de ello es la emergencia y fuerza de nuevos mecanismos de participación que la sociedad civil está haciendo valer en ámbitos tan importantes como la política y la economía.

Cabe destacar al respecto, el interés que ha despertado entre los Estados, las instituciones, las empresas y organizaciones económicas y la sociedad civil en la implementación de sistemas whistleblowing de alertas y denuncias de irregularidades ético-legales, cuyo principal objetivo es sistematizar la gestión de las denuncias por incumplimiento de la normativa interna y externa para prevenir y/o actuar sobre posibles casos de mala praxis.

El sistema whistleblowing se viene desarrollando desde que en 1971 Ralph Nader promoviese la necesidad de aplicarlo en instituciones y organizaciones a raíz de la publicación de diferentes escándalos que salpicaron tanto a la administración pública norteamericana como a ciertas organizaciones económicas de su país (Nader, 1971:43). Este sistema es definido en un primer momento como aquel "acto de un hombre o una mujer que, en la creencia de que el interés público prevalece sobre el interés de la organización a la que sirve, públicamente "hace sonar el silbato" si la organización está involucrada en actividades corruptas, ilegales, fraudulentas o perjudicial" (Nader et al, 1972:vii). La idea giraba en torno al diseño de un mecanismo de prevención de malas prácticas para empresas, organizaciones económicas y administraciones públicas, pero también para evitar que se vinculara al denunciante con términos despectivos como soplón o chivato (Nader, 1971:43; Nader et al, 1972).

Después de tres décadas de desarrollo teórico-práctico, el sistema se empezó a consolidar e implementar gracias a la aprobación en 2002 de la conocida Ley Sarbanes-Oxley (SOX), elaborada por Sarbanes y Oxley (2002) y promulgada por el Congreso Norteamericano como medida de prevención y control de las sociedades cotizadas $^{3}$. Fue entonces cuando distintas empresas, organizaciones y clústeres de diferente calado se cercioraron de su potencial como sistema de monitorización del comportamiento para gestionar el cumplimiento de la normativa y las directrices internas y externas así como fomentar la participación comprometida de los agentes. Es decir, a través de ello se motivaba y potenciaba la implicación de las partes interesadas en el correcto desarrollo de la organización, logrando de esta forma prevenir conflictos cuya emergencia podrían tener efectos

3 Artículos de la Ley SOX más importantes al respecto: 302, 401, 404, 409, 802 y 906. 
negativos sobre la consecución de un máximo beneficio económico ${ }^{4}$.

A su diseño y consolidación también han contribuido diferentes normativas, directrices y estándares internacionales aparecidos durante los últimos años. Cabe destacar al respeto, los Principios de Gobierno Corporativo de la Organización para la Cooperación y el Desarrollo Económicos (OCDE) (2004:4041): principio III. Tratamiento equitativo de los accionistas y IV. El papel de las partes interesadas en el Gobierno Corporativo, en los que se insta a las organizaciones a establecer "procedimientos y "puertos seguros" para recoger denuncias relativas a comportamientos ilegales o poco éticos presentadas por los empleados".

De igual forma, la Actualización de la estrategia de la Organización Internacional del Trabajo (OIT) en materia de recursos humanos, que a través de su Artículo 8. Denuncias de irregularidades (Whistleblowing) (OIT, 2000:16), promueve la gestión de aquellas "reclamaciones que tengan por objeto una preocupación razonable y sincera con respecto a la legalidad de cualesquiera prácticas laborales relativas a las condiciones de trabajo o de empleo (whistleblowing)".

Por otra parte el Global Compact, especialmente con el desarrollo de su "Principio 10: Anticorrupción" (Naciones Unidas, 1999); exige a las empresas firmantes que trabajen "contra la corrupción en todas sus formas, incluidas extorsión y soborno". Asimismo, la Norma ISO 26000 sobre responsabilidad social, mediante su apartado 6.3.6 Asunto 4 sobre derechos humanos: resolución de reclamaciones (ISO, 2010:30) y 4.4 Compromiso ético, impulsa entre las organizaciones y empresas "el establecimiento y el mantenimiento de mecanismos para facilitar que se informe sobre comportamientos no éticos sin miedo a represalias" (ISO, 2010:12).

Todas estas normativas han resultado claves. En este sentido las aportaciones provenientes del Sistema de gestión de la responsabilidad social IQNet SR10, mediante su apartado 8.6. No conformidad, acción correctiva $y$ acción preventiva (2011:37) (IQNet, 2012), reclama que la organización implemente y mantenga "uno o varios procedimientos para tratar las no conformidades reales (incluidas las quejas y reclamaciones de los grupos de interés) y potenciales, y adoptar las acciones correctivas y las acciones preventivas"

Asimismo, el programa Responsible Care del sector químico, a través de su Principio Guía 2. Participación de los trabajadores y su Principio Guía 3, Evaluación y prevención de riesgos, insta a las organizaciones adheridas a que asignen "recursos humanos y técnicos para identificar los peligros, evaluar y gestionar los riesgos potenciales inherentes a sus procesos y productos, dedicando especial atención a la prevención y control de accidentes (Federación Empresarial de la Industria Química Española -FEIQUE-, 1993).

Por otro lado, las recomendaciones del Consejo Europeo a través del Dictamen 1/2006 elaborado por el Grupo de Trabajo del Artículo 29 sobre Protección de Datos mediante su apartado IV.1 Legitimidad de los sistemas de denuncias de irregularidades ofrece una serie de sugerencias para la correcta implantación y tratamiento del sistema whistleblowing (Consejo Europeo, 2006:7-10). 
Finalmente, cabe señalar las contribuciones de la Resolución sobre la adopción de normas por la Unión Europea para las empresas europeas que operan en países en desarrollo: Hacia un código de conducta europeo a través del apartado Mecanismo europeo destinado a garantizar la observancia de las normas (European Parliament, 1999:128); de los estándares específicos $B S i$ Whistleblowing Arrangements Code of Practice (British Standards Institute, 2008), ECS2000: A Guidance Document for the Implementation of the Ethics Compliance Standard 2000 (Reitaku University Business Ethics and Compliance Research Center, 1999) y Australian Standard AS8000 (1999); y de la guía G.4 Sustainability Reporting Guidelines, a través de los indicadores G.4-49, G.457 y G.4-58 (Global Reporting Iniciative, 2014:40, 42).

Desde los diferentes casos prácticos y de las distintas orientaciones provenientes de estas normas, directrices y estándares internacionales señalados es posible dilucidar un diseño de sistema whistleblowing de alertas y denuncias de irregularidades ético-legales que, estructurando alrededor cuatro pilares fundamentales -Responsable de cumplimiento, Oficina de cumplimiento, Línea de cumplimiento y Política de cumplimiento- puede estar a la altura de las expectativas en juego.

El Responsable de cumplimiento constituye el máximo responsable de la gestión de las denuncias, del control del sistema y del correcto funcionamiento de los canales y mecanismos implicados. Éste suele tener voz en el Consejo de Dirección o, en el menor de los casos, disponer de un canal de comunicación directo con el CEO de la empresa. Además, es la persona que se preocupa de que la investigación sobre las alertas y/o denuncias sea ágil y efectiva, informando del proceso y su resolución a los implicados, controlando que se satisfagan los plazos establecidos, y verificando que se apliquen las medias correctoras pertinentes.

La Oficina de cumplimiento, dirigida normalmente por el Responsable de cumplimiento, es el órgano que se preocupa de la gestión de las denuncias y de la prevención de malas práctica éticolegales. Para ello, éstas suelen poner en marcha programas de concienciación de la cultura empresarial, de los valores y principios, de fomentar la participación activa y comprometida de los partes interesadas en todo el proceso, y de gestionar las denuncias, ofreciendo un servicio de asistencia, asesoramiento y/o información al denunciante y monitorizando el correcto funcionamiento de los canales y mecanismos de comunicación del sistema.

La Línea de cumplimiento, gestionada por la Oficina de cumplimiento y orientada a la comunicación con los trabajadores, directivos y accionistas de la organización, constituye el conjunto de canales internos y externos establecidos por la organización para asesorar y recibir alertas, sugerencias y/o denuncias de irregularidades de carácter ético y legal. En cuanto a los canales internos, suelen utilizarse oficinas, departamentos 0 directivos implicados en lagestióny correcto desarrollo del sistema whistleblowing. Por ejemplo, el Responsable de cumplimiento, la Oficina de cumplimiento, el Comité de cumplimiento, el Departamento de Derecho Legal, un supervisor de área, o incluso el propio CEO.

En cuanto a los canales de comunicación externos, éstos hacen referencia a aquellos canales que permiten al whistleblower comunicarse con un asesor externo e independiente a la organización para conocer si su 
alerta o denuncia tiene fundamento $y$ los pasos a seguir para formalizarla. Por ejemplo, un abogado externo que, contratado por la organización, ofrezca servicio de asesoramiento jurídico al whistleblower, tanto sobre sus derechos y responsabilidades como sobre si el caso concreto es susceptible o no de ser denunciado. Así, la Línea de cumplimiento, ya sea a nivel interno o externo, suele estructurarse alrededor de uno o varios canales de comunicación complementarios, entre los que destaca el teléfono interno y/o externo; el correo electrónico $\mathrm{y} / \mathrm{o}$ postal; la ventanilla de registro de informes y consultas; las entrevistas y consultas cara a cara, el servicio de contestador telefónico; los cuestionarios de opinión y satisfacción; los informes de cumplimiento ético-legal, las auditorías de cumplimiento, entre otros.

La Política de cumplimiento, elaborada por la organización, es el documento guía donde se plasma el protocolo básico de gestión y actuación, el Plan estratégico de cumplimiento, las normas y directrices implicadas, los objetivos y compromisos, las propuestas de mejora, las sanciones aplicables, los tiempos, los procesos de investigación, derechos y deberes de los denunciantes y denunciados, los procesos de auditoria y monitorización del sistema, y demás cuestiones importantes relativas a los procesos de cumplimiento.

A través de una correcta implantación e implementación de, al menos, estos cuatro elementos fundamentales, laimplantación eimplementación del emergente sistema whistleblowing de monitorización del cumplimiento éticolegal puede ayudar a las organizaciones económicas a gestionar la participación activa de las partes implicadas y/o afectadas por sus acciones y decisiones $y$, con ello, a gestionar la ética para estar a la altura de lo exigible y deseable por una sociedad madura, con un nivel postconvencional de desarrollo moral; es decir, a dirigir su actividad hacia ese horizonte que le da sentido y legitimidad.

Ahora bien, a pesar de las posibles ventajas que podría aportar a la organización la implementación de un sistema whistleblowing de monitorización del comportamiento ético-legal, el actual sistema es importante pero insuficiente para una gestión eficaz y eficiente de la ética a nivel organizacional, puesto que, como se ha comentado a lo largo de este estudio, lo moral no emerge de algo concreto y aislado, sino que se construye, enriquece y legitima a través de la participación de los afectados. Por ello, entiendo que la organización necesita complementarlo con otros mecanismos de comunicación para poder gestionar la ética en su ámbito de actividad.

Así, desde el sistema integrado de gestión ética diseñado por GarcíaMarzá (2004:229-240), se sugiere que la organización debería empezar por a) definir los valores y principios morales que conforman el carácter de la organización y aquellas normas de conducta relacionadas cuya violación pueden ser causa de corrección o punición -código de ética y conducta-; b) establecer espacios para la deliberación de las partes interesadas sobre aquellos conflictos relativos al comportamiento moral -comité de ética-; c) concretar una metodología para la recogida selectiva, el procesamiento, el análisis y la difusión de la información sobre sus impactos materiales en materia económica, social y medioambiental -informe de ética y responsabilidad corporativa-; y d) establecer un mecanismo de control y mejora de los diferentes procesos y mecanismos del sistema de gestión de la ética implantado -auditoría ética- 


\section{Conclusiones}

A través de la propuesta integrativa de Ulrich y el enfoque hermenéuticocrítico de Conill, este estudio ha presentado la ética como un factor clave del correcto desarrollo de la economía y de la satisfacción de un máximo beneficio empresarial. Entre otras cosas, porque en un contexto económico global como el actual, la legitimidad y credibilidad de los procesos, acciones y decisiones exige respeto a los valores y principios universalizables que defienden las sociedades con un nivel postconvencional de desarrollo moral, y la reflexión moral ayuda a ello mediante la concreción del marco prescriptivo que permite a las instituciones y organizaciones económicas estar a la altura de tales exigencias y expectativas.

Ambas visiones han mostrado, además, quelaaplicacióneimplementación de la ética en los diferentes contextos de actividad económica requiere de la participación comprometida de la sociedad civil para constituirse y potenciarse correctamente. De ahí que el estudio se ha preocupado de ofrecer orientaciones para su gestión en la práctica organizacional a través de la aplicación e implementación de varios mecanismos de comunicación: código de ética y conducta, memoria de ética y responsabilidad corporativa, comité de ética, auditoría ética y línea ética.

Se trata, pues, de complementar un sistema de monitorización whistleblowing y un sistema integrado de gestión ética para lograr promover y potenciar la participación comprometida de los grupos de interés en las actividades y toma de decisiones de la organización, mejorar la concreción de acuerdos con las partes interesadas y orientar sus acciones y decisiones hacia el horizonte de sentido que le es propio y del cual emerge la legitimidad moral que le permite desarrollar bienes comunicativos tan importantes para la satisfacción del beneficio económico como la confianza, la reputación, la afinidad o la reciprocidad.

Por tanto, con este trabajo se han ofrecido orientaciones para el diseño de un sistema de monitorización y gestión de la ética que podría mejorar los procesos de gestión y control del comportamiento moral en las organizaciones económicas. Un sistema cuya aplicación e implementación permitiría llevar a la práctica el enfoque hermenéutico-crítico de economía ética desarrollado por Jesús Conill; un enfoque desde el cual es posible afrontar con garantías los retos que subyacen al proceso actual de globalización económica.

\section{Referencias bibliográficas}

Apel, Karl-Otto (1985), La transformación de la filosofía. Tomo II. El a priori de la comunidad de comunicación, España, Taurus.

Apel, Karl-Otto (2003), Globalización y necesidad de una ética universal. $\mathrm{El}$ problema a la luz de una concepción pragmático-trascendental y procedimental de la ética discursiva, Razón pública y éticas aplicadas. Los caminos de la razón práctica en una sociedad pluralista, España, Tecnos, pp. 191-218

British Standards Institute (2008), BSi Whistleblowing Arrangements Code of Practice, Reino Unido.

Calvo, Patrici (2012), Racionalidad económica: aspectos éticos de la reciprocidad, España, Publicacions de la Universitat Jaume I.

Calvo, Patrici (2013), Neuro-racionalidad: heterogeneidad motivacional $y$ compromiso moral, Daimon. Revista Internacional de Filosofía, $\mathrm{N}^{\circ}$. 59, pp. 157-170.

Calvo, Patrici (2014), Ética empresarial, responsabilidad social y bienes 
comunicativos, Tópicos. Revista de Filosofía, $\mathrm{N}^{\circ}$. 47, pp. 199-232.

Calvo, Patrici y Erikson, Stefan (2014), Civil society participation in the management of the common good: a case of ethics in biological resource centres, Recerca. Revista de Pensament i Anàlisi, №. 15, pp. 7-19.

Camps, Victoria y Cortina Adela (2007), Las éticas aplicadas, La aventura de la moralidad (paradigmas, fronteras y problemas de la ética), España, Alianza editorial, pp. 444-463.

Caseres, Javier (2011), Ética, economía y política, España, ESIC Editorial.

Comas, José (2007), Siemens gastó 420 millones en sobornos, EI País, 11/02/2007. Disponible en: http:// elpais.com/diario/2007/02/11/ econo/1171148401_850215.html, Fecha de consulta: $\overline{15}$ de noviembre de 2014.

Conill, Jesús (2000a), Globalización y ética económica, Papeles de ética, economía y dirección, $\mathrm{N}^{\circ}$. 5, pp. 1-8.

Conill, Jesús (2000b), Marco ético-económico de la empresa moderna, La ética de la empresa. Claves para una nueva ética empresarial, España, Trotta, pp. 51-74.

Conill, Jesús (2003a), El carácter ético y deliberativo de las éticas aplicadas, Razón pública y éticas aplicadas. Los caminos de la razón práctica en una sociedad pluralista, España, Tecnos, pp. 121-142.

Conill, Jesús (2003b), El sentido ético de la economía en tiempos de globalización, Revista de Filosofía, №. 29, pp. 9-15.

Conill, Jesús (2006a), Ética Hermenéutica. Crítica desde la facticidad, España, Tecnos.

Conill, Jesús (2006b), Horizontes de economía ética, España, Tecnos.

Consejo Europeo (2006), Dictamen 1/2006 elaborado por el Grupo de Trabajo del Artículo 29 sobre Protección de Datos (EUWP), Unión Europea.

Cortina, Adela (1990), Ética sin moral, España, Tecnos.

Cortina, Adela (1993), Ética aplicada y democracia radical, España, Tecnos.
Cortina, Adela (1996), El estatuto de la ética aplicada. Hermenéutica crítica de las actividades humanas, Isegoría, $\mathrm{N}^{\circ}$. 13, pp. 119-134.

Cortina, Adela (2000), Ética de la empresa. La ética de la empresa. Claves para una nueva ética empresarial, España, Trotta, pp. 75-94.

Cortina, Adela (2003), El quehacer público de las éticas aplicadas, Razón pública y éticas aplicadas. Los caminos de la razón práctica en una sociedad pluralista, España, Tecnos, pp. 13-44.

Cortina, Adela (2007), Ética de la razón cordial. Educar en la ciudadanía en el siglo XXI, España, Nobel.

Cortina, Adela (2010), Justicia cordial, España, Trotta.

Cortina, Adela (2011), Ciudadanía democrática: ética, política y religión, Isegoría. Revista de Filosofía Moral y Política, $\mathrm{N}^{\circ}$. 44, pp. 13-55.

Cortina, Adela (2013), Ética del discurso: ¿un marco filosófico para la neuroética?, Isegoría. Revista de Filosofía Moral y Política, $\mathrm{N}^{\circ}$. 48, pp. 127-148.

Cortina, Adela (2014), ¿Para qué sirve realmente la ética?, España, Paidos.

Cortina, Adela y Martínez, Emilio (1996), Ética, España, Akal.

Donati, Pierpaolo (2013), Sociologia relazionale. Come cambia la società, Italia, La Scuola.

Donati, Pierpaolo y Calvo, Patrici (2014), New Insight into Relational Goods, Recerca. Revista de Pensament i Anàlisi, $\mathrm{N}^{\circ}$. 14, pp. 7-17.

Escario, José L. (2014), El edén perfecto de las multinacionales, El País, 07/11/2014. Disponible en: http://internacional. elpais.com/internacional/2014/11/07/ actualid/1415383878 428921. html?rel=rosEP, Fecha de consulta: 15 de noviembre de 2014.

European Parliament (1999), Resolución sobre la adopción de normas por la Unión Europea para las empresas europeas que operan en países en desarrollo: Hacia un código de conducta europeo, Unión Europea.

Faus, Joan (2013), Los 'Lobbies' alargan su poder en la sombra en Washington, EI País, 25/11/2013. Disponible 
en: $\quad$ http://internacional.elpais. com/internacional/2013/11/25/ actualidad/1385391136_931553.html, Fecha de consulta: 15 de noviembre de 2014

Feenstra, Ramón A. (2012), Democracia monitorizada en la era de la nueva galaxia mediática. La propuesta de John Keane, España, Icaria.

Feenstra, Ramón A. y Casero, Andreu (2014), Democracy in the digital communication environment: A typology proposal of political monitoring processes, International Journal of Communication, $\mathrm{N}^{\circ}$. 8, pp. 2448-2468.

Federación Empresarial de la Industria Química Española (FEIQUE) (1993), Responsible Care, Unión Europea, ICCA.

Fernández, Diana (2010), Nepotismo y amiguismo empresarial, CNN Expansión, 07/06/2010. Disponible en: http://www.cnnexpansion.com/ emprendedores/2010/06/07/elnepotismo-y-amiguismo-empresarial, Fecha de consulta: 15 de noviembre de 2014].

García-Marzá, Domingo (1992), Ética de la justicia. J. Habermas y la ética del discurso, España, Tecnos.

García-Marzá, Domingo (2004), Ética empresarial: del diálogo a la confianza, España, Trotta.

González, Elsa (2001), La responsabilidad moral de la empresa: una revisión de la teoría de los Stakeholders desde la ética discursiva, España, Publicacions de la Universitat Jaume I.

Govea, Héctor y Rodríguez, Isabel (2009), Capital social, desarrollo endógeno y gestión de demandas ciudadanas, Revista Venezolana de Gerencia, Vol.14, N. 45, pp. 55-77.

Gómez, Manuel V. y Méndez, Rafael (2014), Coches de lujo, dietas, marisco y viajes con cargo a la Seguridad Social, El País, 14/06/2014. Disponible en: http://economia. elpais.com/economia/2014/06/14/ actualidad/1402767982_756157.html, Fecha de consulta: $15 \overline{\text { de noviembre }}$ de 2014.
Global Reporting Iniciative (2014), G4 Sustainability Reporting Guidelines, Holanda.

Habermas, Jürgen (1991), Escritos sobre moralidad y eticidad, España, Paidós.

Habermas, Jürgen (1999), La inclusión del otro, España, Paidós.

Habermas, Jürgen (2000), Aclaraciones a la ética del discurso, España, Trotta.

International Organization for Standardization (ISO) (2010), Norma ISO 26000: 2010, Italia, ISO.

IQNEet (2012), IQNet SR10 Sistema de Gestión de la Responsabilidad Social, Requisitos, Suiza.

Nader, Ralph (1971), A code for profesional integrity; Three basic changes to end the silence in organizational life, New York Times. Business and Finance, p. 43, $15 / 01 / 1971$.

Nader, Ralph, Petkas, Peter y Blackwell, Kate (Editores) (1972), Whistle Blowing, USA, Bantam.

Noceda, Miguel A. (2010), La imparable politización de las cajas, El País 7/02/2010. Disponible en: http:// elpais.com/diario/2010/02/07/ negocio/1265551404_850215.htmlç, Fecha de consulta: $1 \overline{5}$ de noviembre de 2014

Organización para la Cooperación y el Desarrollo Económicos (OCDE) (2004), Principios de Gobierno Corporativo de la OCDE. Disponible en: http://www.oecd.org/daf/ 